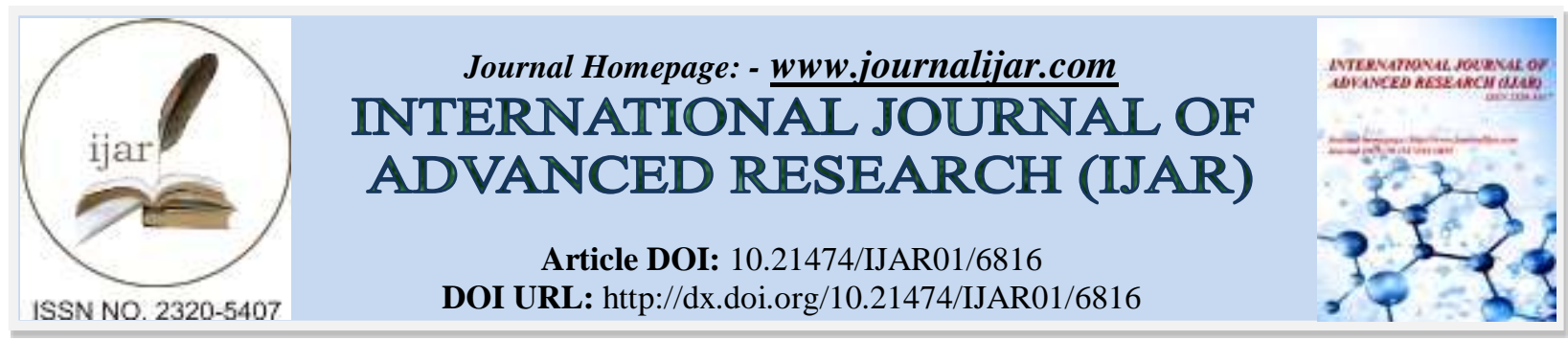

RESEARCH ARTICLE

\title{
CHRONIC BULLOUS DISEASE OF CHILDHOOD (CBDC): (CASE REPORT).
}

Mohamed Amin Gebreel Md ${ }^{1}$, Amira Ali Zaakok $\mathrm{Md}^{2}$ and Hazem Mohamed Skr Msc ${ }^{3}$.

1. Lecturer of Pediatrics, Faculty of medicine, Al Azhar University, Cairo, Egypt.

2. Consultant Dermatology, Faculty of medicine, Al Azhar University, Cairo, Egypt.

3. Specialist Dermatology, Faculty of medicine, Al Azhar University, Cairo, Egypt.

\section{Manuscript Info}

Manuscript History

Received: 22 January 2018

Final Accepted: 24 February 2018

Published: March 2018

Keywords:-

chronic bullous disease of childhood (CBDC), linear IgA dermatosis, Dapson, Prednisolone.

\begin{abstract}
Linear IgA bullous disease is an acquired, autoimmune, vesiculobullous disease. Its name comes from linear deposition of immunoglobulin class (A)along the dermoepidermal junction when detected by direct immunofluorescence .Both children and adults are affected. Both sexes are equally affected with slight female predominance.In children it is referred as chronic bullous disease of childhood (CBDC). It affects children mainly between 1 and 11 years with peak between 6 and 8year. All races are affected but more common in developing countries.Its onset is acute and usually severe while recurrences become less severe. Diaminodiphenylsulfone (Dapsone) is the treatment of choice, in addition to systemic corticosteroids. We reported an 8-year-old boy with a vesiculobullous eruption which developed suddenly without any preceding infection or drugs in the previous two weeks. He complained of moderate itching diagnosed as scabies and received topical anti scabitic medications, with worsening of symptoms and appearance of new lesions.He was diagnosed as having contact dermatitis. The patient had many vesiculobullous and erosive lesions in the face, trunk, gentalia and back with sparing of palms and soles. We diagnosed him clinically as having (CBDC) and admitted in our hospital. Biopsy was taken from newly erupted intact vesicles for histopathology and prelesinal skin for immunofluorescence and soon we started Dapsone $2 \mathrm{mg} / \mathrm{kg} / \mathrm{day}$. After immunohistological verification, the treatment with oral prednisone $1 \mathrm{mg} / \mathrm{kg} /$ day hadbeen started.
\end{abstract}

Copy Right, IJAR, 2018,. All rights reserved.

\section{Introduction:-}

Linear IgA disease is defined as an autoimmune, non hereditary, subepidermal, blistering disease of unknown etiology. Its name comes from linear deposition of $\operatorname{IgA}$ along the dermoepidermal junction seen by immunofluorescence. ${ }^{(1)(2)}$

The incidence is not fully known but itis around 1:500.000.The age of onset in children from 1 to 11 years, with the peak between 6 to 8 years. ${ }^{(3)}$

CBDC occurs less frequently in children, usually as a response to drug hypersensitivity or neoplasm ${ }^{(4)}$

Address:- Lecturer of Pediatrics, Faculty of medicine, Al Azhar University, Cairo, Egypt. 
As many as two-thirds of CBCD are related to drug, particularly certain antibiotics, non steroidal anti inflammatory drugs and diuretics. ${ }^{(5)}$

The hallmark of this disorder is the abrupt appearance of many large, tense bullae, filled with clear or haemorrhagic fluid and acquiring the typical rosette-like pattern of 'string of pearlscluster of jewels'on normal or erythematous skin .Bullae appear in the genital,buttocks, trunk, extremities,face and mucous membranes. Secondary impetiginisationis frequent, but scarringis not common. The disease is often self-limiting, but may persist for months or even years, with occasional recurrences, before complete resolution, usually by puberty. ${ }^{(4)}$

\section{Case report:}

An 8year-old boy was refered to The Department of Dermatology of IbnSina College General Hospital,Jedda, Saudi Arabia, complaining of intense pruritus for one week, diagnosed as scabies and received topical antiscabitic drugs for five days with woresening of the condition and referred to our derma clinic as having contact dermatitis.

A written and informed consent was taken for investigations,publication process as well as photos.

Thorough history taking and full clinical examination revealed ; vitally stable condition ,his weight $15 \mathrm{~kg}$ (below 5 th percentile), height was $114 \mathrm{~cm}$ (just below 5th percentile) he was pale with no jaundice or cyanosis.Systemic examination was free. Skin examination revealed;annular and grouped papules, vesicles, and bullae symmetrically distributed upon extensor surfaces ("cluster of jewels").

The hairs, nails and mucous membranes were intact.

We admitted the patient and did the following investiagtions;

CBC; showed an elevated white blood cell count $\left(24.000\right.$ cells $\left./ \mathrm{mm}^{3}\right)$.With neutrophils $(69 \%$,), lymphocytosis (18\%) monocytes( $11 \%$ )esinophils (2\%) monocytes (11\%) and basophi;( $0 \%)$.

Other tests; renal and liver function tests, (ALT, AST albumin, globulin A/G ratio ,alkaline phosphatase, total and directbilirubin),blood sugar, $\mathrm{CRP}$, urine analysis, chest X-ray and complement tests (C3, C4), were within the normal limits. We did quantitative G6PD assay before Dasone therapy (not defecient).

We started Dapson $2 \mathrm{~m} / \mathrm{kg} /$ day $(30 \mathrm{mg}$ ) for one week without improvement thus we statred oral prednisolone $1 \mathrm{mg} / \mathrm{kg} /$ day in divided doses after confirmation by immnunoflurescence.

Both drugs continue for 6 weeks. We repeated laboratory investigations weekly . After that we gradually stopped oral prednisolone and watching for any new lsions. One week after stoppage of corticosteroids exacerbation occurred and new lesions appeared. Again we started oral predinsolone for another course for 3 weeks with complete recovery without any new lesions. We continued Daspone alone for 6 months. We did not find any side effects as regard treatment either Dapsone or Prednisolone.

We followed our patient with: (1)complete blood cell count and liver function tests at baseline, (2) a complete blood cell count weekly for the first month, then monthly for next 6 months, and (3) liver function tests every month. In addition we followed body weight, blood pressure and blood glucose for possible corticosteroid side effects. 

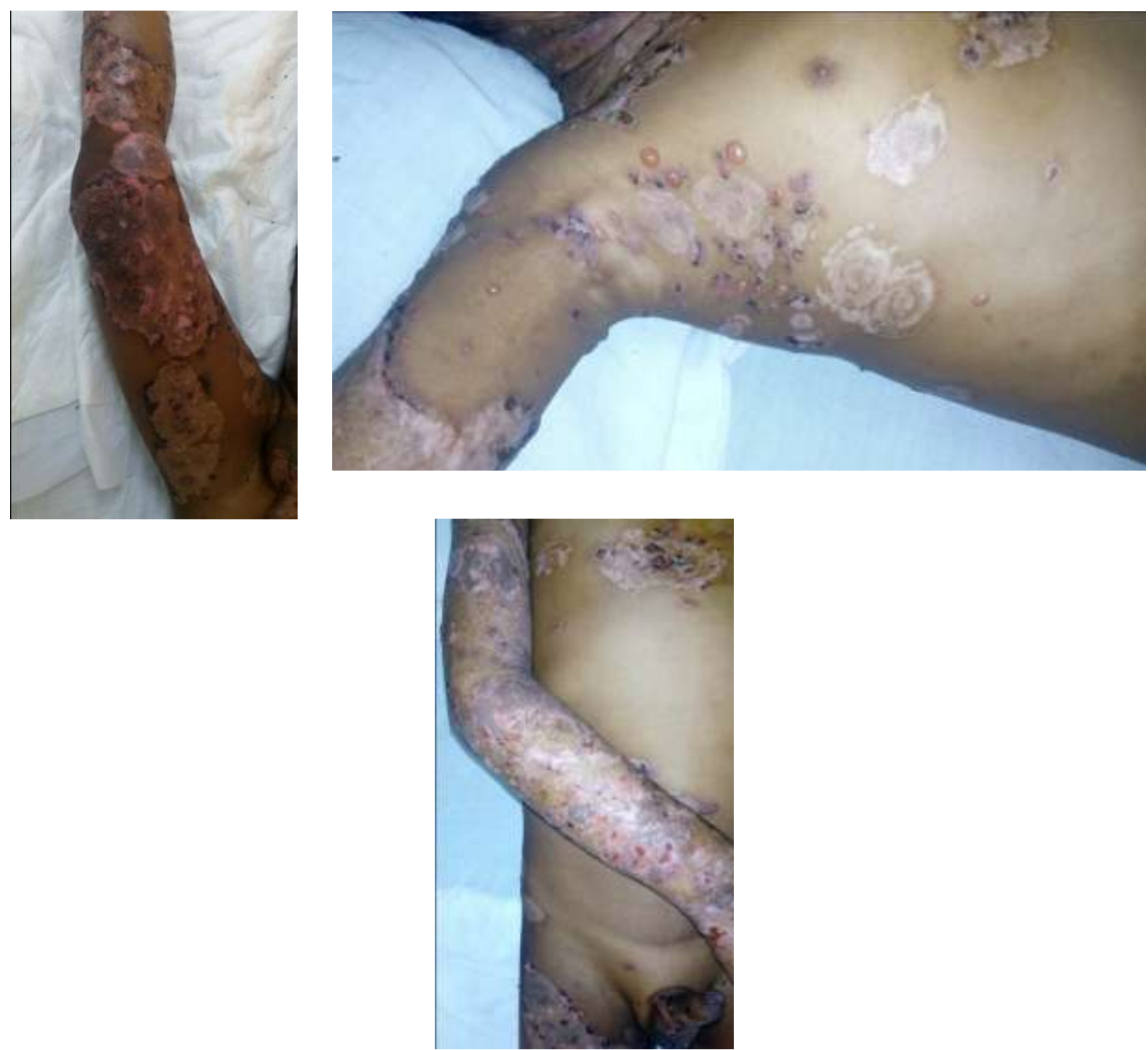

figure 1:- before treatment.

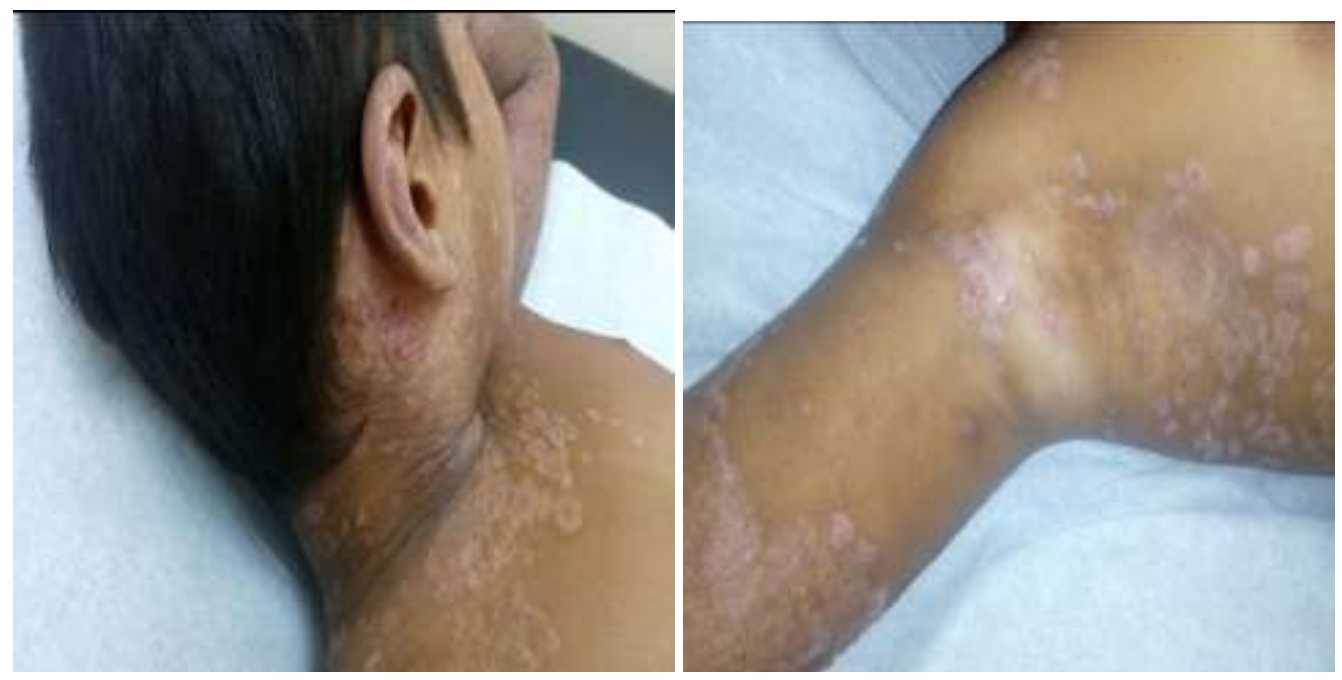

Figure 2:- after combined Dapsone and Prednisolone treatment. 


\section{Discussion:-}

Haneef et al. ${ }^{(6)}$ stated that all pediatric cases with the typical finding of cluster of jewels sign considered as CBDC irrespective of the nature of the immune deposits, as there are cases show IgG predominance not IgA. Blister formation results from the activation of plasminogen to plasmin by keratinocytes as well as activation of neutrophils leading to the activation of promatrix metalloproteinase 9 and neutrophil elastase. Plasmin cleaves collagen type XVII ,so fragments may be recognized as immunogenic epitopes (including a 97-kDa fragment) in the serum of patient with this disease. ${ }^{(7),(8) \text {. }}$

Diagnostic confirmation by direct immunofluorescence studies, where IgA linear deposition at the dermaoepidermaljunction can be observed. Theses antigens distributed beneath the hemidesmosome or just on the lamina densa or beneath it ${ }^{(9)}$ This determines the humoral response in CBCD. A cellular response is also involved with complement activation, recruitment of inflammatory cells and release of proteolytic enzymes . ${ }^{(10)}$

In settings, where such diagnostic method is not available, diagnosis remains clinical, after exclusion of other diseases such as erythema multiforme, bullous pemphigoid and dermatitis herpetiformis . ${ }^{11)}$

The majority of cases respond well to long-term oral Dapsone, or Sulfapyridine. Alternatively, systemic corticosteroids or Tacrolimus can be effective and sometimes may need topical or oral antibiotics. ${ }^{(4)}$

In our case there is poor response to Dapsone $2 \mathrm{mg} / \mathrm{kg} / \mathrm{day}$ for 7 days with marked improvement after initiation of oral prednisolone $1 \mathrm{mg} / \mathrm{kg} /$ day but we noticed one exacerbation after stoppage of oral corticosteroids with complete remission after finishing the second course of corticosteroids.

\section{Conclusion:-}

We present a 8-year-old boy in whom diagnosis of chronic bullous dermatosis of childhood was established according to clinical, histopathological and direct immunofluorescence findings. The clinical follow up confirmed a remission after 6 weeks treatment with both Dapson and oral Prednisolone and one excerbatuion attake after stoppage of prednosolone and so corticosteroid therapy augment the effect of Dapsone as well as prevents exacerbations.

\section{Declaration of Conflicting Interest:-}

The authors declare that they have no competing interests.

\section{Funding:-}

Funding was not received from another sources

\section{Refrences:-}

1. Wilson BD, Beutner EH, Kumar V, Chorzelski TP, Jablonska S. Linear IgA bullous dermatosis. An immunologically defined disease. Int J Dermatol. 1985;24:569-74.

2. Chan LS, Traczyk T, Taylor TB, Eramo LR, Woodley DT, Zone JJ. Linear IgA bullous dermatosis. Characterization of a subset of patients with concurrent $\operatorname{IgA}$ and $\operatorname{IgG}$ anti-basement membrane autoantibodies. Arch Dermatol 1995;131:1432-7.

3. Polat M, Lenk N, Kürekçi E et al. Chronic bullous disease of childhood in a patient with acute lymphoblastic leukemia: possible induction by a drug. Am J ClinDermatol. 2007; 8: 389-391

4. Varo, M., Fernández SL, Sitoe, A., Bassat Q.,(20170 Suspected case of chronic bullous disease of childhood in a rural area of Southern Mozambique .BMJ Case Rep 2017. doi:10.1136/bcr-2016-218315

5. Ho JCC, Ng PLP, Tan SH et al. Childhood linear IgA bullous disease triggered by amoxicillin-clavulanic acid. PediatrDermatol. 2007; 24: E40-43.

6. Haneef NS, Ramachandra S, Metta AK, Srujana L (2012) Chronic bullous disease of childhood with IgG predominance: what is the locus standi? Indian J Dermatol 57: 285-287.

7. Liu Z, Li N, Diaz LA, Shipley M, Senior RM, et al. (2005) Synergy between a plasminogen cascade and MMP9 in autoimmune disease. J Clin Invest 115: 879-887.

8. Hofmann SC, Voith U, Schönau V, Sorokin L, Bruckner-Tuderman L, et al. (2009) Plasmin plays a role in the in vitro generation of the linear IgA dermatosis antigen LADB97. J Invest Dermatol 129: 1730-1739. 
9. Horiguchi Y, Ikoma A, Sakai R, Masatsugu A, Ohta M, Hashimoto T. Linear IgA dermatosis: report of an infantile case and analysis of 213 cases in Japan. J Dermatol. 2008;35:737-743

10. Lin MS, Fu CL, Olague-Marchan M, Hacker MK, Zillikens D, et al. (2002) Autoimmune responses in patients with linear IgA bullous dermatosis: both autoantibodies and T lymphocytes recognize the NC16A domain of the BP180 molecule. ClinImmunol 102: 310-319.

11. Patsatsi A. Chronic bullous disease or linear IgA dermatosis of childhood—revisited. J Genet Syndr Gene Ther 2013;4:151. 